TITLE:

\title{
How Individual States and Traits Predict Aesthetic Appreciation of Haiku Poetry
}

$\operatorname{AUTHOR}(\mathrm{S})$ :

Hitsuwari, Jimpei; Nomura, Michio

CITATION:

Hitsuwari, Jimpei ...[et al]. How Individual States and Traits Predict Aesthetic Appreciation of Haiku Poetry. Empirical Studies of the Arts 2022, 40(1): 81-99

ISSUE DATE:

2022-01

URL:

http://hdl.handle.net/2433/266465

\section{RIGHT:}

This is the accepted manuscript of the following article: Jimpei Hitsuwari, Michio Nomura. How Individual States and Traits Predict Aesthetic Appreciation of Haiku Poetry. Empirical Studies of the Arts, 40(1) pp. 81-99. Copyright @ 2022 (SAGE Publications). DOI: 10.1177/0276237420986420.; This is not the published version. Please cite only the published version.この論文は出版社版でありません。引用の際には出版社版をご確認ご利用ください。 
How Individual States and Traits Predict Aesthetic Appreciation of Haiku Poetry

\author{
Jimpei Hitsuwari and Michio Nomura
}

Department of Cognitive Psychology, Graduate School of Education, Kyoto University

\title{
Author Note
}

Jimpei Hitsuwari https://orcid.org/0000-0002-0061-5318

Michio Nomura https://orcid.org/0000-0003-1043-2811

This research was supported by Grants-in-Aid for Scientific Research (KAKENHI;

JSPS KAKENHI grant no. 19H01773).

Correspondence concerning this article should be addressed to Michio Nomura, Kyoto University, Yoshida Honmachi, Sakyo Ward, Kyoto, 606-8501, Japan. Email: 


\begin{abstract}
The factors influencing poetry's aesthetic appreciation are largely unknown. Some studies have reported features that affect the aesthetic appreciation of poetry. This study sought to determine which states and traits predict the aesthetic appeal of haiku poetry. We recruited 277 participants to rate 36 haiku on five characteristics: imagery vividness, stimulus valence, arousal, valence of felt emotion, and aesthetic appeal of haiku. Then, participants completed questionnaires that assessed their own traits. We found both valence of felt emotion and imagery vividness generally predicted haiku's aesthetic appeal; additionally, the influence of imagery vividness on aesthetic appeal was partially mediated by valence of felt emotion. As mental imagery fosters emotional evocation, vivid imagery increases positive felt emotions associated with aesthetic appeal. Furthermore, the traits of visual imagery ability, awe-proneness, and nostalgia-proneness predicted haiku's aesthetic appeal. This study advances our knowledge of how individual states and traits determine the aesthetic appeal of haiku.

Keywords: aesthetic appreciation, haiku poetry, emotion, mental imagery, personality
\end{abstract}




\section{How Individual States and Traits Predict Aesthetic Appreciation of Haiku Poetry}

The factors that influence aesthetic appreciation of poetry are largely unknown. Numerous studies of aesthetic perception, appreciation, and emotion exist, and relevant structural models have been constructed (e.g., Chatterjee \& Vartanian, 2014; Jacobsen, 2006, 2010; Leder et al., 2004; Leder \& Nadal, 2014; Menninghaus et al., 2019). For example, Jacobsen (2006) noted that seven main categories can influence aesthetic experience, such as content, personality traits, or cognitive and emotional states (i.e., psychological states) as well as their subcategories. Based on these models, numerous studies on the psychology of aesthetics have been published, using paintings (e.g., Cupchik et al., 2009; Hosoya, 2020; Konecni, 2015), music (e.g., Bannister, 2020; Jackendoff \& Lerdahl, 2006; Koelsch, 2014), and films (e.g., Fröber \& Thomaschke, 2019; Hanich et al., 2014; Silvia \& Berg, 2011) as stimuli. However, although poetry has the potential to evoke strong emotion (Wassiliwizky et al., 2017) and serves as optimal material for the study of empirical aesthetics in terms of metrics and features, psychological research on poetry is still in the formative stage (Jacobs, 2015; Figure 1). Nevertheless, some researchers have reported factors associated with aesthetic appreciation of poetry, focusing on the content, psychological states, and personality traits in the aesthetic experience of poetry.

\section{Poetry Content and Aesthetic Appreciation}

The factors that predict the aesthetic appreciation of poetry, including rhetorical structure and length of poetry (Aryani et al., 2016; Menninghaus et al., 2015, 2017b; Obermeier et al., 2013, 2015; Wassiliwizky et al., 2017), have been examined. However, these have predominately focused on how poetic devices affect the reader's comprehension, appreciation, and recollection of the poem (Lüdtke et al., 2014). 
Participants typically evaluate poems as more rhythmical, melodious, and harmonious compared with other literature, such as novels (Knoop, et al., 2016). Rhetorical structures are poetry-specific, and previous studies on the aesthetic appreciation of poetry have focused on such content to a relatively large extent (Belfi et al., 2018). As aesthetic preferences are influenced not only by the content or stimulus but also by psychological states or personality traits of subjects (Jacobsen, 2006, 2010; Jacobsen \& Höfel, 2002; Leder, 2004), aesthetic appreciation has been considered from the perspective of psychological states and personality traits (Jacobsen, 2006). Therefore, in the current study, we also considered psychological states and personality traits.

\section{Psychological States and Aesthetic Appreciation}

First, researchers have found that emotions are predominately involved in response to art (e.g., Silvia, 2009), with abundant discussion regarding valence and arousal with visual images (e.g., Hagtvedt et al., 2008) and music (e.g., Stratton \& Zalanowski, 1994). For example, ratings of emotional valence are more predictive of liking visual artworks than are ratings of image comprehension (Leder et al., 2012). In addition, as subjective ratings of ambiguity predict liking photographs of artworks (Muth et al., 2015) and emotional feelings of fluency are more robustly related to liking than fluency of images (Forster et al., 2013), subjective features of art are key components in the formation of aesthetic experiences. Although a few studies have been conducted on poetry, Wassiliwizky et al. (2017) showed that the emotional peak of poetry reading (listening) was not randomly found, but was seen at the end point of lines or stanzas. In another instance, Hilscher and Cupchik (2005) set three conditions for the participants: reading poems, listening to poems, and seeing the poem performance. They then asked participants to evaluate the poems using the General 
Poetry Questionnaire and Poetry Reception Questionnaire. As a result, they found that participants showed different responses to the three types of conditions and preferred the reading poems condition the most.

Such emotional evaluations have been found to be related to mental imagery (Holmes \& Mathews, 2005; Holmes et al., 2006). For instance, Belfi et al. (2018) adopted haiku poetry as a stimulus and assessed the relationships between mental imagery and aesthetic appreciation. They found that the more vivid participants' mental images were, the greater their aesthetic appreciation became; imagery vividness was the best predictor of the aesthetic appeal of haiku. The question then arises: How does vivid imagery lead to high aesthetic appeal? Considering that imagery may influence emotion by regulating, enhancing, or evoking moods (e.g., Holmes et al., 2006), we hypothesized that mental images may also increase positive or negative emotions associated with an aesthetic experience.

\section{Personality Traits and Aesthetic Appreciation}

In contrast, the effect of personality traits on aesthetic appreciation of artworks has been investigated predominantly using paintings and music as stimuli. For example, aesthetic appreciation is related to individual differences in the Big Five personality traits (Rosenbluh et al., 1972; Tran et al., 2019), ambiguity tolerance (Child \& Chapman, 1973; Swami et al., 2010), and trait empathy (Vuoskoski et al., 2012). While a small number of studies have considered poetry, Sundararajan (2004) showed that individual traits, such as autonomy, the nonconformist dimension of openness, and intrinsic motivation, lead to creativity as one aspect of aesthetic experience. In addition, Belfi et al. (2018) found that scores on the Vividness of Visual Imagery Questionnaire (VVIQ; Marks, 1973), which assesses individual differences in visual imagery abilities, were 
moderately related to the aesthetic appeal of haiku.

Furthermore, recent studies have focused on individual differences in mixed emotions (Larsen \& McGraw, 2011) and mixed appraisals (Barford et al., 2018). Among them, awe - an emotion characterized by the perception of vastness and need for accommodation (Keltner \& Haidt, 2003) — is known to be of two types: positive awe and threatened awe (Sawada \& Nomura, 2020). Aesthetic experience is mostly related to positive awe, as the neural correlation between experiencing positive awe and the anterior and posterior cingulate cortices associated with aesthetic reward processes has been revealed (Takano \& Nomura, 2020). For example, Silvia et al. (2015) found that the personality trait of openness to experience predicted feeling mixed emotion awe during an aesthetic experience of music. Researchers have considered awe in the domain of aesthetics as well as the deep relationship between aesthetic emotions and awe. Individuals may feel awe in response to nature, music, and mathematical formulae, among others, although cultural differences typically exist in these responses. For example, Japanese people tend to feel awe more strongly in the relationship between the self and others or natural disasters than do individuals from Western cultures (Nomura et al., in press).

In addition, nostalgia — defined as "a sentimental longing for one's past" (Sedikkides et al., 2008) is also known as mixed emotion connected to aesthetic experience (Brattico et al., 2013). For example, Specht and Kreiger (2016) revealed that people who tend to feel nostalgia like paintings including human figures more and judge them as more thought-provoking than those without this trait. While many studies regarding the relationship between personality traits and artworks have focused on paintings and music, we examined the relationship between aesthetic experience and 
personality traits using haiku poetry, which depends on one or two core images (Blasko \& Merski, 1998; Greene et al., 2012), as an ambiguous aesthetic stimulus. For example, when we read one of the most famous haiku poems "The ancient pond/A frog leaps in/The sound of the water," we could imagine pond and frog.

\section{Purpose}

In the present study, we investigated how psychological states and personality traits affect the aesthetic appeal of poetry. First, we explored the relationship between the aesthetic appeal of haiku and participants' states, such as experiencing vivid imagery. Belfi et al. (2018) indicated that the state in which people experience vivid mental imagery predicts its aesthetic appeal. That study revealed that the more vivid the mental imagery evoked in people, the higher they rated the aesthetic appeal of haiku; however, the underlying mechanisms of this connection have remained unknown. Belfi et al. (2018) further suggested that felt emotion, especially its valence, would be a mediator on the relationship between vivid imagery and aesthetic appeal of haiku based on the research that mental imagery influenced emotions (e.g., Holmes et al., 2006; Pearson et al., 2015). Thus, in the present study, we hypothesized that imagery vividness would predict the aesthetic appeal of haiku (RQ1), and that this relationship would be mediated by the valence of emotions experienced by the participant (RQ2).

Second, we investigated the relationship between aesthetic appreciation of haiku and participants' personality traits, such as openness to experience and visual imagery ability. We also tentatively explored the relationship between appreciation and the personality traits of awe-proneness and nostalgia-proneness. Therefore, we assessed whether the personality traits of openness to experience, visual imagery abilities, awe-proneness, and nostalgia-proneness are correlated with aesthetic appreciation of 
haiku (RQ3).

\section{Method}

\section{Participants}

This study was approved by the Ethics Committee of Kyoto University

(CPE-317). Participants were recruited using CrowdWorks, a Japanese crowdsourcing service (https://crowdworks.jp).

Participation was restricted to Japanese individuals with verified ID. In total, 300 participants were recruited and were asked to answer two questionnaires in total on two days. However, 13 participants on day 1 and 10 participants on day 2 were excluded because they failed to complete the questionnaire, leaving a total of 277 participants $\left(M_{\text {age }}=38.68\right.$ years, $S D=10.24 ; 209$ female, 68 male $)$.

\section{Materials}

The haiku were chosen from a collection (Fujimoto et al., 2013) because this collection encompasses a variety of haiku from the late nineteenth century, some of which are very famous, while others are less well known. Standard haiku consist of a prescribed 5-7-5 syllable form and usually include one word related to a season.

In a preliminary study, five people rated haiku in terms of whether they could imagine the situation described in the poem. Haiku were excluded if the situation described could not be imagined by more than two people, leaving 111 haiku. The themes of the haiku were spring $(n=22)$, summer $(n=26)$, autumn $(n=33)$, winter $(n=$ 24), and New Year $(n=6)$.

\section{Procedure}

The research consisted of two parts, which took place on two separate days. In the first part, participants were instructed to read a description of the study and complete 
the Positive and Negative Affect Schedule (PANAS; Watson et al., 1988). After reading the instructions about how to rate the poems, participants read one haiku. After seven seconds, the response scales were shown on screen. The poem was rated on six dimensions, in the following order, consistent with the scale used in Belfi et al. (2018): (a) aesthetic appeal ("How enjoyable or aesthetically appealing did you find this poem?”), (b) vividness I (“How vivid is the imagery evoked by this poem?”), (c) vividness II ("How easy was it to visualize the imagery evoked by the poem?”), (d) arousal (“How relaxing or stimulating was this poem?”), (e) stimulus valence ("How positive or negative was the content of this poem?"), and (f) valence of felt emotion (“How positive or negative did you feel when you read this poem?"). Participants made ratings on a continuous scale using a slider bar with values ranging between $0-100$. Then, participants advanced to the next poem. Each subject saw 36 haiku of the list presented in random order. At the end of the testing session, each participant was asked to review the first five haiku to assess test-retest reliability within participants.

In the second part, participants completed the questionnaire, which included the VVIQ (Marks, 1973), the "openness to experience" subscale of the Japanese Version of the Ten Item Personality Inventory (TIPI-J; Oshio et al., 2014), the "awe" subscale of the Dispositional Positive Emotion Scales (DPES-awe; Shiota et al., 2006), and the Nostalgia-proneness Scale (Kusumi, 2014) to measure visual imagery ability, openness to experience from the Big Five personality traits, awe-proneness, and nostalgia-proneness, respectively. This was completed one to three days after completion of the haiku ratings. Finally, participants completed a short demographic questionnaire. The experiment required approximately 40 minutes to complete and participants were paid 350 yen for completing the task. 


\section{Data Analysis}

The main aim of this study was to elucidate which psychological states and personality traits predict aesthetic appreciation of haiku poetry. Considering participants rated many haiku poems, we used multi-level analysis after calculating intraclass correlation coefficients (ICCs) using the lme4 package in R (ver. 3.6.1). The variables vividness, arousal, stimulus valence, and valence of felt emotion were centered within individuals (group mean centering) before they entered the models.

The second goal was to reveal how vivid mental images foster aesthetic appeal of haiku poetry. We analyzed this aspect using a multi-level mediation approach, which was implemented in Mplus (Preacher \& Hayes, 2008).

\section{Results}

\section{Predictors of Aesthetic Appeal}

Correlations indicated high test-retest reliability for aesthetic appeal $(r=.64)$, vividness I $(r=.71)$, vividness II $(r=.70)$, arousal $(r=.56)$, stimulus valence $(r=.59)$, and valence of felt emotion $(r=.62)$. As vividness I and II were strongly correlated ( $r$ $=.95, p<.001$ ), we used vividness I as "vividness," which was the same item used for "vividness" in the study of Belfi et al. (2018). We calculated the descriptive statistics: distributions of the state variables (Figure 2) as well as the means, medians, and standard deviations (SD) for all variables, the intraclass correlations, and multi-level correlations between all variables (Table 1). When ICCs are greater than 0.1 , the multi-level model is appropriate (Lee, 2000); thus, we conducted multi-level analyses. Moreover, the between-participant level shows the overall trend, while the within-participant level shows the trend for each individual. Based on the multi-level modeling of psychology of aesthetics (e.g., Silvia, 2007), we regarded 
within-participant level as important because there is no strong standard for aesthetic evaluation.

Predictors of the aesthetic appeal of haiku were assessed using a hierarchical linear model, in which the independent variable was aesthetic appeal and the dependent variables were vividness, arousal, stimulus valence, and valence of felt emotion as the psychological states; nostalgia-proneness, awe-proneness, VVIQ, openness to experience, and PANAS as the personality traits; and their interactions. After the initial analysis, we omitted variables that were not significant predictors and then reanalyzed the model (Table 2). The second model exhibited better fit $\left(\chi^{2}(23)=7138.52, p<.01\right.$, $\mathrm{AIC}=81909.75)$ than the first $\left(\chi^{2}(44)=7285.28, p<.01, \mathrm{AIC}=81935.45\right)$. In the second model, haiku poems were nested within individuals. Of the psychological states, the best predictor of the aesthetic appeal of haiku poetry was valence of felt emotion $(b$ $=.44, S E=.02, d f=265.11, t=22.31, p<.01)$, followed by vividness $(b=.19, S E$ $=.01, d f=251.96, t=15.19, p<.01)$, arousal $(b=-.09, S E=.01, d f=261.89, t=15.19$, $p<.01)$, and stimulus valence $(b=.08, S E=.02, d f=257.70, t=4.44, p<.01)$.

We also focused on the relationship between aesthetic appeal and personality traits. According to the results of a hierarchical linear model, aesthetical appeal was predicted by nostalgia-proneness $(b=1.15, S E=.02, d f=276.35, t=2.71, p=.01)$, awe-proneness $(b=1.85, S E=.62, d f=274.61, t=2.98, p=.00)$, and VVIQ $(b=4.02$, $S E=.91, d f=237.75, t=4.42, p<.01)$. Finally, there was significant interaction between vividness and openness to experience $(b=.03, S E=.01, d f=237.75, t=3.03$, $p<.01)$

Further, in order to investigate RQ2, we used multi-level mediation analyses to test whether valence of felt emotion mediated the effect of vividness on aesthetic appeal 
(Figure 3). We included three variables: "aesthetic appeal" as the dependent variable, "vividness" as the independent variable, and "valence of felt emotion" as the mediator. In the within-participant level, there were significant effects of imagery vividness on aesthetic appeal $(b=.19, S E=.02, z=12.50, p<.01)$, imagery vividness on valence of felt emotion $(b=.32, S E=.01, z=22.67, p<.01)$, and valence of felt emotion on aesthetic appeal $(b=.50, S E=.02, z=21.24, p<.01)$. Additionally, in the between-participant level, there were significant effects of imagery vividness on aesthetic appeal $(b=.26, S E=.06, z=4.22, p<.01)$, imagery vividness on valence of felt emotion $(b=.54, S E=.07, z=7.72, p<.01)$, and valence of felt emotion on aesthetic appeal $(b=.79, S E=.08, z=10.01, p<.01)$. The model showed better model fit for the baseline model $(\chi 2(6, N=277)=1742.95, p<.01)$. However, when we assessed model fit by evaluating the chi-square value for model fit, comparative fit index (CFI), and root-mean-square error of approximation (RMSEA), the model was saturated model so that the fit indices of this model were maximum scores $\left(\chi^{2}(0)=0, p\right.$ $=.00, \mathrm{CFI}=1.00, \mathrm{RMSEA}=.00)$.

Therefore, the multi-level mediation analysis indicated that valence of felt emotion partially mediated the relationship between aesthetic appeal and imagery vividness at both levels. At the between-participant level, it was found that participants whose imagery came to mind more vividly tended to report increased positive emotions, resulting in higher aesthetic appeal of haiku. At the within-participant level, it was found that the haiku that brought the imagery to mind more vividly tended to evoke more positive emotions, resulting in higher aesthetic appeal of haiku. As the mediation effects occurred at both the haiku and participant levels, the mechanism seems to depend on both the degree to which each participant's imagery came to mind more 
vividly and the degree to which each haiku aroused the image more vividly.

\section{Discussion}

In this study, we examined whether and how psychological states and personality traits affect aesthetic appreciation of haiku. Valence of felt emotion, vividness of imagery within the poems, arousal due to content, and stimulus valence predicted aesthetic appeal. In particular, the effects of valence of felt emotion and vividness were notably large. These results partially replicate those of the study of Belfi et al. (2018), which also found that imagery vividness and stimulus valence predicted the aesthetic appeal of haiku. Additionally, we newly found that the influence of imagery vividness on the aesthetic appeal of haiku was partially mediated by valence of felt emotion. Further, the traits of visual imagery ability, awe-proneness, and nostalgia-proneness also predicted the aesthetic appeal of haiku.

Valence of felt emotion and imagery vividness were the best predictors of the aesthetic appeal of haiku. This result expands the previous notion (Belfi et al., 2018) that imagery vividness predicts the aesthetic appeal of haiku. Mental imagery fosters the evocation of emotion (Holmes et al., 2006), such that the more vivid the haiku imagery generated by participants is, the more they experienced positive emotions regarding the poem's aesthetic appeal. Given that increasing some positive or negative emotions can also induce pleasant emotions, which are strongly involved in aesthetic appreciation (Leder \& Nadal, 2014), it is reasonable that such emotions can intensify the aesthetic appreciation of haiku.

In general, people who feel strong positive emotions tend to have high appreciation of aesthetic experiences (Prinz, 2011). This is consistent with the present results, whereby participants evaluated more haiku as positive rather than negative. In 
addition, we found that most poems had positive valence and evoked positive emotion in the present study. Musical stimuli with negative content do not always evoke negative emotion; for example, sad music can induce pleasant emotion in an aesthetic context (Brattico et al., 2016; Kawakami et al. 2013; Vuoskoski \& Eerola, 2012; for review, see Sachs et al., 2015). It is of interest to investigate whether and how negative content of poetry, as well as positive content, evokes pleasant emotions.

The present study's results also revealed that three personality traits (visual imagery ability, awe-proneness, and nostalgia-proneness) predicted the aesthetic appeal of haiku. This finding is consistent with a previous study that revealed visual imagery abilities were related to the aesthetic appeal of haiku (Belfi et al., 2018). In addition, we newly demonstrated that the awe-prone or nostalgia-prone personality trait partially determined the aesthetic appeal of haiku. Although openness to experience and DPES-awe were correlated $(r=.29, p<.01$; Table 1 ), as in previous studies (Shiota et al., 2006; Silvia et al., 2015), aesthetic appreciation was not correlated with openness to experience $(r=.10, p=.11)$ but with awe-proneness $(r=.32, p<.01)$. These results suggest that awe-specific properties that openness to experience cannot explain may influence aesthetic appreciation. Unlike paintings and music, the information contained within poetry is typically at a higher level; poems require one to find beauty using semantic information, update one's own schema (i.e., an awe-specific feature), and thereby enjoy the aesthetic experiences.

We found that participants who tended to feel more nostalgia had high appreciation for haiku, which is partially consistent with the results of the study of Specht and Kreiger (2016), who used paintings as stimuli. It should be noted that most haiku used in this study were composed between the early and mid-twentieth century, 
and included old sentence-final particles (kireji), such as " $y a$ " or "kana," and old words. In that sense, the haiku were nostalgia-evoking art. Therefore, individuals with high nostalgia-proneness, namely those who often reminisce about or long for their past, might have felt closer to and familiar with the haiku, and thus found them more beautiful. In terms of openness to experience, this study is inconsistent with previous studies involving paintings (e.g., Rosenbluh et al., 1972), movies, and literature (e.g., Tran et al., 2019). This may be because haiku has a long history and is included in school curricula; thus, the participants might not have found haiku to be novel. To measure openness to experience, we used the TIPI-J (Oshio et al., 2014), with the items “open to new experiences, complex" and "conventional, uncreative." This represents a personality scale for novelty; thus, we did not find correlations between openness to experience and the traditional art of haiku.

Present research has brought new insight into the aesthetics of poetry. However, there has been less research on the aesthetics of poetry than that of music of paintings, and much of it has focused on rhetorical techniques, such as temporal signatures, rhyme, and metaphor. Lüdtke et al. (2014) suggested that there should be more discussion regarding the characteristics of the viewer, such as emotion and empathy, and their interaction with the work. In particular, the influence of background and foregrounding, as expressed in Jacobs' (2015) model, has been a major determinant of the aesthetic experience of all literary works, including poetry. Background is a familiar word or situation model that facilitates the viewer's mental processing of appreciation (i.e., increasing fluency), causing an immersive experience. Foregrounding, in relation to background, employs rhetorical techniques — such as rhyme, metaphor, and unfamiliar phrases - to capture attention and trigger emotional responses (Jacobs, 2015). While 
these are known to form the aesthetic experience of literature as they interacted with each other, when we turned to the haiku used in this study, we found that there was little background and foregrounding. In other words, it is an artform that takes only 17 syllables to complete; hence, there is no context or predictability to form a background and no rhyme or surprising events to form foregrounding. In this context, the evocation of vivid imagery as well as the accompanying emotional experience and affective personality traits that were the focus of this study are elements that characterize the aesthetic experience of haiku. Thus, the study of aesthetics in haiku may be an exciting research topic that will accentuate previous studies of aesthetics in poetry that have relied on the presence of background and foregrounding.

\section{Limitations}

Although we used multi-level analyses, investigated at both the within- and between-participant levels, and revealed the effect of vividness on the aesthetic appeal of haiku through felt emotion, aesthetic appeal and valence of felt emotion were still highly correlated (within-participant: $r=.55$, between-participant: $r=.81$ ). This indicated a possibility that the two variables were not well separated in this study. Valence is one aspect of felt emotion; however, we should assess other dimensions or specific emotions, such as joy and sadness. In addition, we did not measure more elaborated felt emotions, such as being moved, nostalgia, or awe, which have been suggested to predict aesthetic experience according to both models of Menninghaus et al. (2017a, 2019). In future studies, given the role of the personality traits of nostalgia- and awe-proneness, we will directly probe felt mixed emotions (i.e., states). This will reveal more sophisticated emotional and cognitive mechanisms that underlie the aesthetic appreciation of haiku poetry. 
Furthermore, although many prior studies have revealed that expert versus non-expert differences cause or moderate the aesthetic appreciation of artworks (e.g., Silvia, 2013), in the current study, we did not measure the experience with haiku poetry, familiarity with haiku, or the extent of art expertise. Even if Japanese students take many haiku classes in school and have been exposed to haiku for extended periods of time, expertise or interest in art may nevertheless influence the aesthetic appreciation of haiku poetry. Thus, future studies should assess the relationship between expertise and aesthetic appreciation of haiku poetry.

\section{Conclusion}

We investigated how psychological states and personality traits influenced the aesthetic appeal of haiku and revealed that both valence of felt emotion and imagery vividness were predictors of the aesthetic appeal of haiku. The influence of imagery vividness on aesthetic appeal was partially mediated via valence of felt emotion. In addition, we found individual differences in the effect of visual imagery ability, awe-proneness, and nostalgia-proneness on the aesthetic appeal of haiku. In conclusion, this work expands the notion of how individual states and traits determine the aesthetic appeal of haiku. 


\section{References}

Aryani, A., Kraxenberger, M., Ullrich, S., Jacobs, A. M., \& Conrad, M. (2016). Measuring the basic affective tone of poems via phonological saliency and iconicity. Psychology of Aesthetics, Creativity, and the Arts, 10, 191-204. https://doi.org/10.1037/aca0000033

Bannister, S. (2020). A survey into the experience of musically induced chills: Emotions, situations and music. Psychology of Music, 48(2), 297-314. https://doi.org/10.1177/0305735618798024

Barford, K. A., Fayn, K., Silvia, P. J., Smillie, L.D. (2018). Individual differences in conflicting stimulus evaluations: Openness/Intellect predicts mixed-valenced appraisals of visual art, Journal of Research in Personality, 73, 46-55. https://doi.org/10.1016/j.jrp.2017.11.006

Belfi, A. M., Vessel, E. A., \& Starr, G. G. (2018). Individual ratings of vividness predict aesthetic appeal in poetry. Psychology of Aesthetics, Creativity, and the Arts, 12(3), 341-350. https://doi.org/10.1037/aca0000153

Blasko, D. G., \& Merski, D. W. (1998). Haiku poetry and metaphorical thought: an invitation to interdisciplinary study, Creativity Research Journal, 11(1), 39-46. https://doi.org/10.1207/s15326934crj1101_5

Brattico, E., Bogert, B., \& Jacobsen, T. (2013). Toward a neural chronometry for the aesthetic experience of music. Frontiers in Psychology, 4, 206. http://dx.doi.org./10.3389/fpsyg.2013.00206

Brattico, E., Bogert, B., Alluri, V., Tervaniemi, M., Eerola, T., \& Jacobsen, T. (2016). It's sad but I like it: the neural dissociation between musical emotions and liking in experts and laypersons. Frontiers in Human Neuroscience, 9, 676. 


\section{https://doi.org/10.3389/fnhum.2015.00676}

Child, I., \& Chapman, L. (1973). Assessment of affective responses conducive to esthetic sensitivity. Review of Research in Visual and Environmental Education, $1(2), 40-52$.

Cupchik, G., Vartanian, O., Crawley, A., \& Mikulis, D. (2009). Viewing artworks: Contributions of cognitive control and perceptual facilitation to aesthetic experience. Brain and Cognition, 70(1), 84-91. https://doi.org/10.1016/j.bandc.2009.01.003.

Forster, M., Leder, H., \& Ansorge, U. (2013). It felt fluent, and I liked it: subjective feeling of fluency rather than objective fluency determines liking. Emotion, 13, 280-289. https://doi.org/10.1037/a0030115

Fröber, K., \& Thomaschke, R. (2019). In the dark cube: Movie theater context enhances the valuation and aesthetic experience of watching films. Psychology of Aesthetics, Creativity, and the Arts. Advance online publication. https://doi.org/10.1037/aca0000295

Fujimoto, M., Imai, S., Inoue, K., Ishida, K., Iwata, Y., Kakutani, M., Kato, K., Nakanishi, Y., Nonaka, R., Takada, M., Tsugawa, E., Yamanishi, M., \& Yamazaki, Y. (Eds.). (2013). Kansho Nihon no Meiku. Kadokawa Publishing Company.

Greene, R. A., Cushman, S., Cavanagh, C., Ramazani, J., \& Rouzer, P. (2012). The Princeton encyclopedia of poetry and poetics. Princeton University press. https://doi.org/10.1515/9781400841424

Hagtvedt, H., Patrick, V. M., \& Hagtvedt, R. (2008). The Perception and Evaluation of Visual Art. Empirical Studies of the Arts, 26(2), 197-218. 


\section{https://doi.org/10.2190/EM.26.2.d}

Hanich, J., Wagner, V., Shah, M., Jacobsen, T., \& Menninghaus, W. (2014). Why we like to watch sad films. The pleasure of being moved in aesthetic experiences. Psychology of Aesthetics, Creativity, and the Arts, 8(2), 130-143. https://doi.org/10.1037/a0035690

Hilscher, M. C., \& Cupchik, G. C. (2005). Reading, Hearing, and Seeing Poetry Performed. Empirical Studies of the Arts, 23(1), 47-64. https://doi.org/10.2190/LGP5-Q4TM-D0U5-W029

Holmes, E. A., \& Mathews, A. (2005). Mental Imagery and Emotion: A Special Relationship? Emotion, $5(4)$ 489 497. https://doi.org/10.1037/1528-3542.5.4.489

Holmes, E. A., Mathews, A., Dalgleish, T., \& Mackintosh, B. (2006). Positive interpretation training: effects of mental imagery versus verbal training on positive mood. Behavior Therapy, 37, 237-247. https://doi.org/10.1016/j.beth.2006.02.002

Hosoya, G. (2020). The artwork and the beholder: A probabilistic model for the joint scaling of persons and objects. Psychology of Aesthetics, Creativity, and the Arts, 14(2), 224-236. https://doi.org/10.1037/aca0000239

Jackendoff, R., \& Lerdahl, F. (2006). The capacity for music: What is it, and what's $\begin{array}{llll}\text { special about } & \text { it?. } & \text { Cognition, }\end{array}$ https://doi.org/10.1016/j.cognition.2005.11.005.

Jacobs, A.M. (2015). Neurocognitive poetics: methods and models for investigating the neuronal and cognitive-affective bases of literature reception. Frontiers in 
Human Neuroscience, 9, 186. https://doi.org/10.3389/fnhum.2015.00186

Jacobsen, T. (2006). Bridging the arts and sciences: A framework for the psychology of aesthetics.

Leonardo, $39(2)$, $155-162$. http://dx.doi.org/10.1162/leon.2006.39.2.155

Jacobsen, T. (2010). Beauty and the brain: culture, history and individual differences in aesthetic appreciation. Journal of Anatomy, 216, 184-191. https://doi.org/10.1111/j.1469-7580.2009.01164.x

Jacobsen, T., \& Höfel, L. (2002). Aesthetic Judgments of Novel Graphic Patterns: Analyses of Individual Judgments. Perceptual and Motor Skills, 95(3), 755-766. https://doi.org/10.2466/pms.2002.95.3.755

Kawakami, A., Furukawa, K., Katahira, K., \& Okanoya, K. (2013). Sad music induces pleasant emotion, Frontiers in Psychology, 4, 311. https://doi.org/10.3389/fpsyg.2013.00311

Keltner, D., \& Haidt, J. (2003). Approaching awe, a moral, spiritual, and aesthetic emotion. Cognition and Emotion. 17, 297-314. https://doi.org/10.1080/02699930302297

Knoop, C., Wagner, V., Jacobsen, T., \& Menninghaus, W. (2016). Mapping the aesthetic space of literature "from below". Poetics, 56, 39-45. https://doi.org/10.1016/j.poetic.2016.02.001

Koelsch, S. (2014). Brain correlates of music-evoked emotions. Nature Reviews Neuroscience, 15(3), 170-84. https://doi.org/10.1038/nrn3666

Konecni, V. (2005). The aesthetic trinity: awe, being moved, thrills. Bulletin of Psychology and the Arts, 5(2), 27-44. https://doi.org/10.1037/e674862010-005

Kusumi, T. (2014). Natsukashisakeiken ni Oyobosu Karei no Eikyo: Nostalgia tono Sai 
no Kento to Keikou Syakudo no Sakusei. The Annual Conference of Japanese Society of Social Psychology, 55, 216. (in Japanese)

Larsen, J. T., \& McGraw, A. P. (2011). Further evidence for mixed emotions. Journal of Personality and Social Psychology, 100(6), 1095-1110. https://doi.org/10.1037/a0021846

Leder, H., Belke, B., Oeberst, A., \& Augustin, D. (2004). A model of aesthetic appreciation and aesthetic judgments. British Journal of Psychology, 95, 489508. https://doi.org/10.1348/0007126042369811

Leder, H., Gerger, G., Dressler, S. G., \& Schabmann, A. (2012). How art is appreciated. Psychology of Aesthetics, Creativity, and the Arts, 6, 2-10. https://doi.org/10.1037/a0026396

Leder, H., \& Nadal, M. (2014). Ten years of a model of aesthetic appreciation and aesthetic judgments: The aesthetic episode - developments and challenges in empirical aesthetics. British Journal of Psychology, 105, 443-464. https://doi.org/10.1111/bjop.12084

Lee, V. E. (2000). Using hierarchical linear modeling to study social contexts: the case of school effects. Educational psychologist, 35, 125-141. https://doi.org/10.1207/S15326985EP3502 6

Lüdtke, J., Meyer-Sickendieck, B., \& Jacobs, A. M. (2014). Immersing in the stillness of an early morning: testing the mood empathy hypothesis of poetry reception. Psychology of Aesthetics, Creativity, and the Arts, 8, 363-377. https://doi.org/10.1037/a0036826

Marks, D. F. (1973). Visual imagery differences in the recall of pictures. British Journal of Psychology, 64, 17-24. https://doi.org/10.1111/j.2044-8295.1973.tb01322.x 
Menninghaus, W., Bohrn, I. C., Knoop, C. A., Kotz, S. A., Schlotz, W., \& Jacobs, A. M. (2015). Rhetorical features facilitate prosodic processing while handicapping ease of semantic comprehension. Cognition, 143, 48-60. https://doi.org/10.1016/j.cognition.2015.05.026

Menninghaus, W., Wagner, V., Hanich, J., Wassiliwizky, E., Jacobsen, T., \& Koelsch, S. (2017a). The distancing-embracing model of the enjoyment of negative emotions in art reception. Behavioral and Brain Sciences, 40, e347. http://dx.doi.org/10.1017/S0140525X17000309

Menninghaus, W., Wagner, V., Wassiliwizky, E., Jacobsen, T., \& Knoop, C. A. (2017b). The emotional and aesthetic powers of parallelistic diction. Poetics, 63, 47-59. https://doi.org/10.1016/j.poetic.2016.12.001

Menninghaus, W., Wagner, V., Wassiliwizky, E., Schindler, I., Hanich, J., Jacobsen, T., \& Koelsch, S. (2019). What are aesthetic emotions? Psychological Review. 126, 171-195. https://doi.org/10.1037/rev0000135

Muth, C., Hesslinger, V. M., \& Carbon, C.-C. (2015). The appeal of challenge in the perception of art: how ambiguity, solvability of ambiguity, and the opportunity for insight affect appreciation. Psychology of Aesthetics, Creativity, and the Arts, 9, 206-216. https://doi.org/10.1037/a0038814

Nomura, M., Tsuda, A., \& Rappleye, J. (in press). Defining awe in East Asia: cultural differences in describing the emotion and experience of awe. In Chiao, J, Shu-Chen, Rebecca, Bob (Eds.), Handbook of Cultural Neuroscience: Cultural Neuroscience and Health. New York: Oxford University Press.

Obermeier, C., Menninghaus, W., Koppenfels, M., Raettig, T., Schmidt K. M., Otterbein, S., \& Kotz S. A. (2013). Aesthetic and emotional effects of meter and rhyme in 
poetry. Frontiers in Psychology, 4, 10. https://doi.org/10.3389/fpsyg.2013.00010

Obermeier, C., Kotz, S. A., Jessen, S., Raettig, T., von Koppenfels, M., \& Menninghaus, W. (2015). Aesthetic appreciation of poetry correlates with ease of processing in event-related potentials. Cognitive, Affective \& Behavioral Neuroscience, 16, 362-373. https://doi.org/10.3758/s13415-015-0396-X

Oshio, A., Abe, S., Cutrone, P., \& Gosling, S. (2014). Further validity of the Japanese version of the Ten Item Personality Inventory (TIPI-J). Journal of Individual Differences, 35, 236-244. https://doi.org/10.1027/1614-0001/a000145

Pearson, J., Naselaris, T., Holmes, E. A., \& Kosslyn, S. M. (2015). Mental imagery: functional mechanisms and clinical applications. Trends in Cognitive Sciences, 19, 590-602. https://doi.org/10.1016/j.tics.2015.08.003

Preacher, K.J., \& Hayes, A.F. (2008). Asymptotic and resampling strategies for assessing and comparing indirect effects in multiple mediator models. Behavior Research Methods, 40, 879-891. https://doi.org/10.3758/BRM.40.3.879

Prinz, J. (2011). Emotion and aesthetic value. In E. Schellekens \& P. Goldie (Eds.), The aesthetic mind: Philosophy and psychology (pp. 71-88). United Kingdom: Oxford University Press.

Rosenbluh, E. S., Owens, G. B., \& Pohler, M. J. (1972). Art preference and Personality. British Journal of Psychology, 63: 441-443. https://doi.org/10.1111/j.2044-8295.1972.tb01293.x

Sachs, M. E., Damasio, A., \& Habibi, A. (2015). The pleasures of sad music: a systematic review. Frontiers in Human Neuroscience, 9, 404. https://doi.org/10.3389/fnhum.2015.00404

Sawada, K., \& Nomura, M. (2020). Influence of Positive and Threatened Awe on the 
Attitude Toward Norm Violations. Frontiers in psychology, 11, 148. https://doi.org/10.3389/fpsyg.2020.00148

Sedikides, C., Wildschut, T., Arndt, J., \& Routledge, C. (2008). Nostalgia: Past, Present, and Future. Current Directions in Psychological Science, 17(5), 304-307. https://doi.org/10.1111/j.1467-8721.2008.00595.x

Shiota, M. N., Keltner, D., \& John, O. P. (2006) Positive emotion dispositions differentially associated with Big Five personality and attachment style. The Journal of Positive Psychology, 1(2), 61-71. https://doi.org/10.1080/17439760500510833

Silvia, P. J. (2007). An introduction to multilevel modeling for research on the psychology of art and creativity. Empirical Studies of the Arts, 25, 1-20. http://dx.doi.org/10.2190/6780-361T-3J83-04L1

Silvia, P. J. (2009). Looking past pleasure: anger, confusion, disgust, pride, surprise, and other unusual aesthetic emotions. Psychology of Aesthetics, Creativity, and the Arts, 3, 48-51. https://doi.org/10.1037/a0014632

Silvia, P. J., \& Berg, C. (2011). Finding movies interesting: how appraisals and expertise influence the aesthetic experience of film. Empirical Studies of the Arts, 29(1), 73-88. https://doi.org/10.2190/EM.29.1.e

Silvia, P. J. (2013). Interested Experts, Confused Novices: Art Expertise and the Knowledge Emotions. Empirical Studies of the Arts, 31(1), 107-115. https://doi.org/10.2190/EM.31.1.f

Silvia, P. J., Fayn, K., Nusbaum, E. C., \& Beaty, R. E. (2015). Openness to experience and awe in response to nature and music: personality and profound aesthetic experiences. Psychology of Aesthetics, Creativity, and the Arts, 9(4), 376-384. 


\section{https://doi.org/10.1037/aca0000028}

Specht, S. M., \& Kreiger, T. C. (2016). Nostalgia and perceptions of artwork. Psychological Reports, $\quad$ 118(1), 57-69. https://doi.org/10.1177/0033294115626818

Stratton, V. N., \& Zalanowski, A. H. (1994). Affective impact of music vs. lyrics. Empirical Studies of the Arts, 12(2), 173-184. https://doi.org/10.2190/35T0-U4DT-N09Q-LQHW

Sundararajan, L. (2004). Twenty-four poetic moods: poetry and personality in Chinese aesthetics. Creativity Research Journal, 16(2-3), 201-214. https://doi.org/10.1080/10400419.2004.9651453

Swami, V., Stieger, S., Pietschnig, J., \& Voracek, M. (2010). The disinterested play of thought: individual differences and preference for surrealist motion pictures. Personality and Individual Differences, 48(7), 855-859. https://doi.org/10.1016/j.paid.2010.02.013

Takano, R., \& Nomura, M. (2020). Neural representations of awe: Distinguishing common and distinct neural mechanisms. Emotion. Advance online publication. https://doi.org/10.1037/emo0000771

Tran, U. S., Swami, V., Seifriedsberger, C., Baráth, Z., \& Voracek, M. (2019). “Kneweth one who makes these notes ...": personality, individual differences, and liking of nouveau roman and existentialist literature and film. Psychology of Aesthetics, Creativity, and the Arts. Advance online publication. https://doi.org/10.1037/aca0000252

Vuoskoski, J., \& Eerola, T. (2012). Can sad music really make you sad? Indirect measures of affective states induced by music and autobiographical memories. 
Psychology of Aesthetics, Creativity, and the Arts, 6(3), 204-213. https://doi.org/10.1037/a0026937

Vuoskoski, J., Thompson, W. F., McIlwain, D., \& Eerola, T. (2012). Who enjoys listening to sad music and why? Music Perception, 29(3), 311-317. https://doi.org/10.1525/mp.2012.29.3.311

Wassiliwizky, E., Koelsch, K., Wagner, V., Jacobsen, T., \& Menninghaus, W. (2017). The emotional power of poetry: neural circuitry, psychophysiology and compositional principles. Social Cognitive and Affective Neuroscience, 12(8), 1229-1240. https://doi.org/10.1093/scan/nsx069

Watson, D., Clark, L. A., \& Tellegen, A. (1988). Development and validation of brief measures of positive and negative affect: the PANAS scales. Journal of Personality and Social Psychology, 54, 1063-1070. https://doi.org/10.1037/0022-3514.54.6.1063 
Results of Hierarchical Linear Model

\begin{tabular}{lrrrrr} 
Number of obs: & \multicolumn{1}{c}{9972} & & & & \\
Groups: & ID, 277 & & & & \\
Random effects: & Name & Variance & SD & & \\
ID & (Intercept) & 85.74 & 9.26 & & \\
Residual & & 221.82 & 14.89 & & \\
Fixed effects: & Estimate & SE & df & t value & p value \\
\hline Intercept) & 58.35 & .58 & 277.00 & 101.29 & $.00 * *$ \\
Vividness & .21 & .01 & 9695.00 & 26.57 & $.00 * *$ \\
Arousal & -.08 & .01 & 9695.00 & -10.67 & $.00 * *$ \\
Stimulus Valence & .06 & .01 & 9695.00 & 4.90 & $.00 * *$ \\
Valence of Felt Emotion & .45 & .01 & 9695.00 & 35.69 & $.00 * *$ \\
Nostalgia Proneness & 1.13 & .43 & 280.20 & 2.64 & $.01 * *$ \\
Awe Proneness & 1.98 & .63 & 277.20 & 3.16 & $.00 * *$ \\
Visual Imagery Ability & 3.92 & .92 & 282.30 & 4.25 & $.00 * *$ \\
Vividness * Openness & .03 & .01 & 9695.00 & 4.94 & $.00 * *$
\end{tabular}

\section{Figure 1}




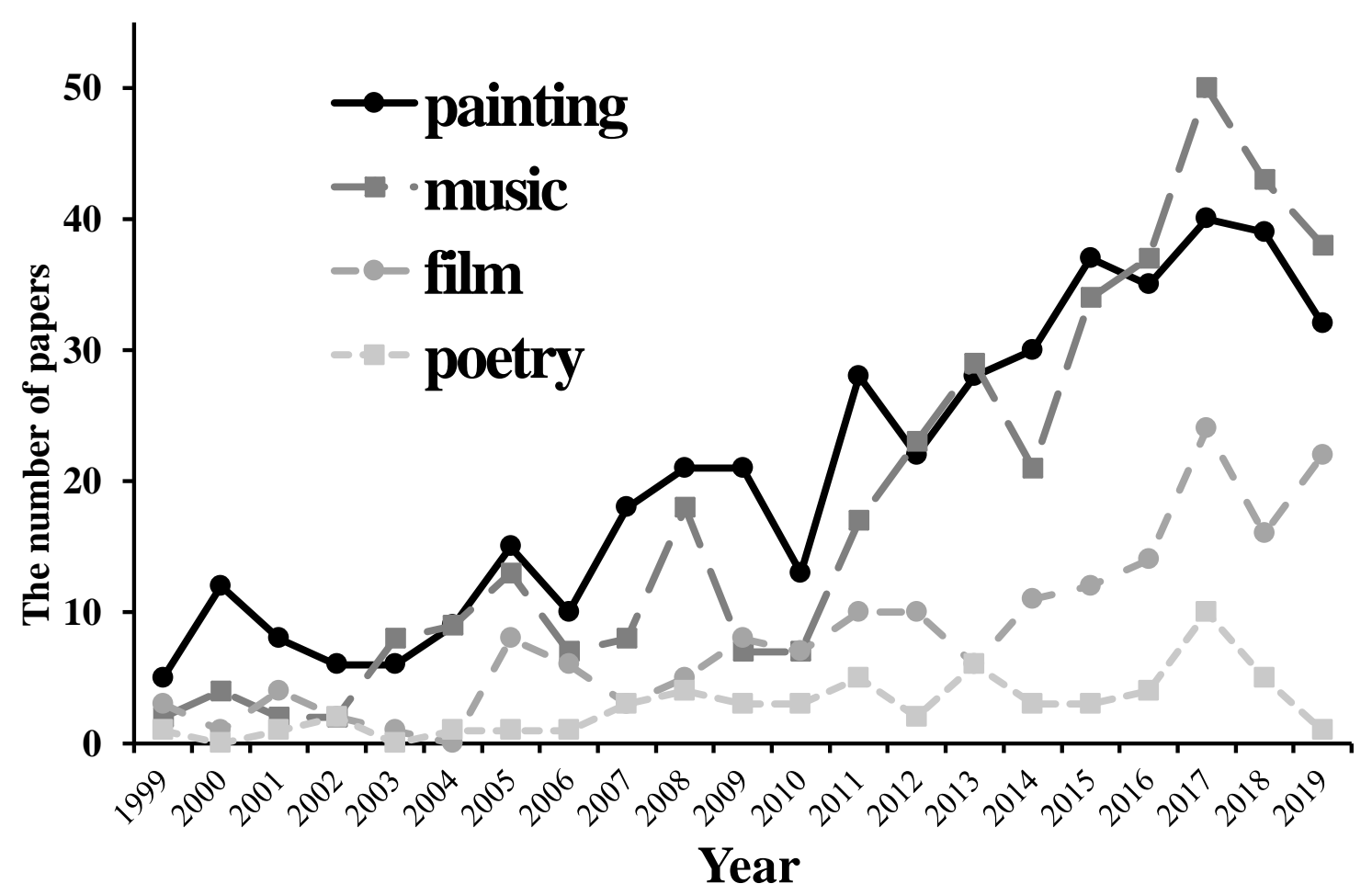

Figure 2 
The histograms for state variables

A
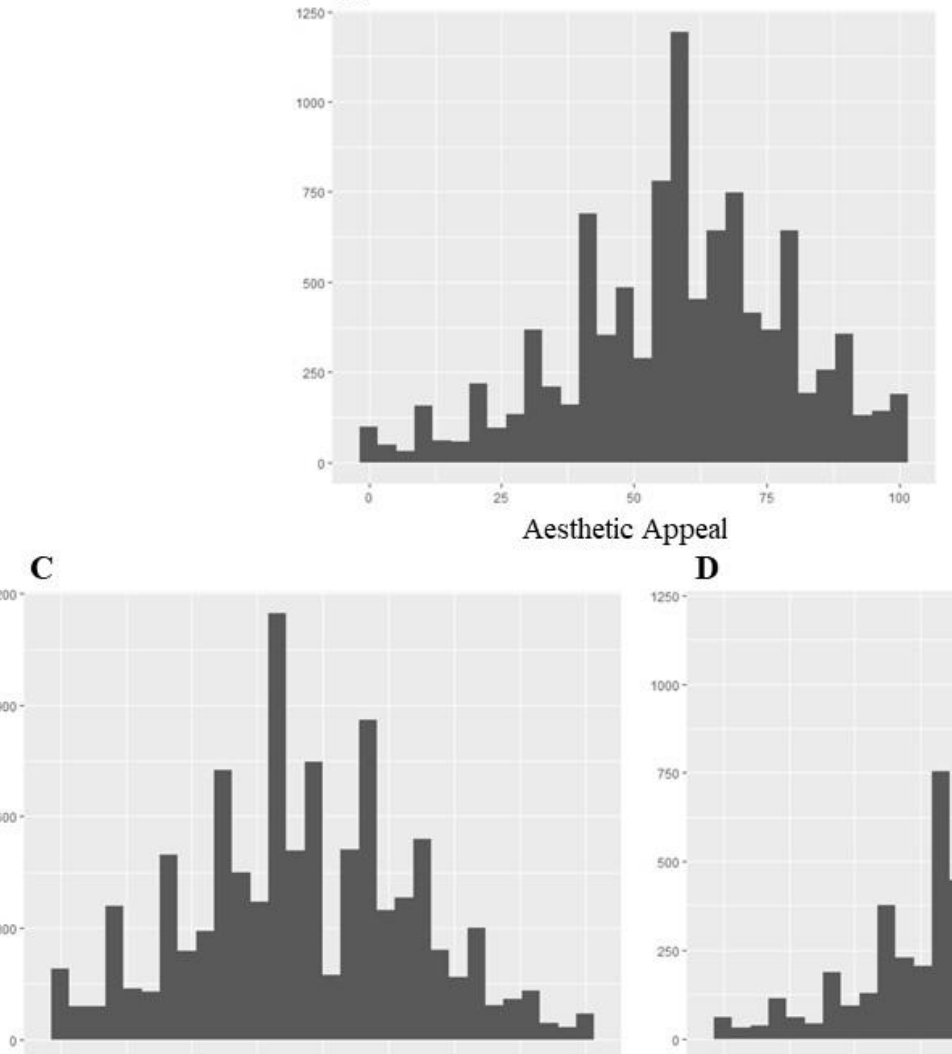

Arousal
D

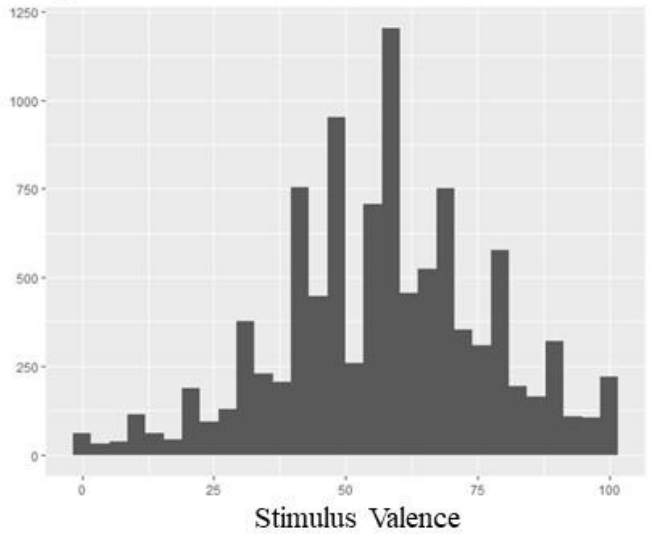

B

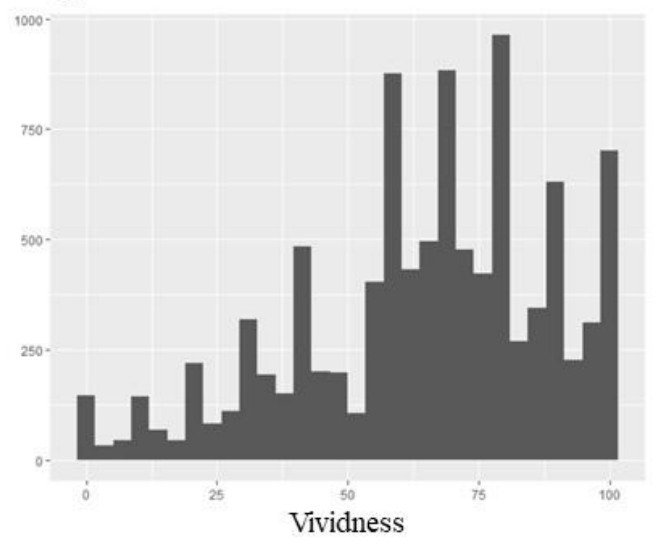

$\mathbf{E}$

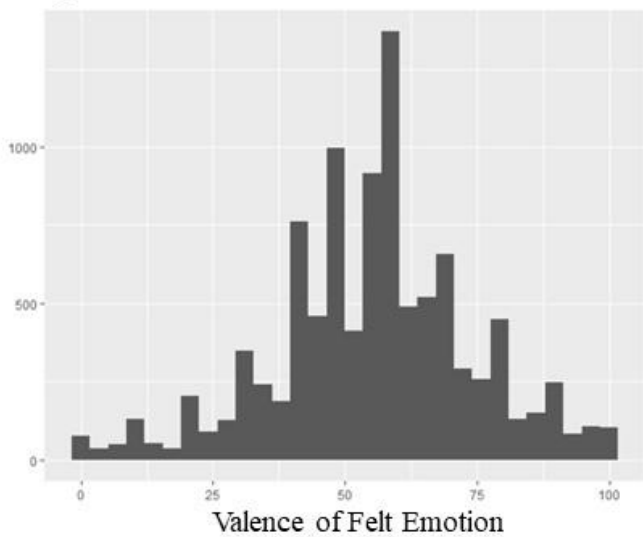

Figure 3 
Multi-level Mediation Effect of Valence of Felt Emotion on the Relationship between Vividness and Aesthetic Appeal (A: within participant level; B: between participant level)

$\mathbf{A}$ Valence of

$.32 * *$ Felt Emotion $.50 * *$

\begin{tabular}{|l|l|l|}
\hline & \\
Vividness & $.35 * * \ldots .19 * *$ & Aesthetic Appeal
\end{tabular}

B

Valence of Felt Emotion $.79 * *$

Vividness

$$
.68^{* *}->.26^{* *}
$$

Aesthetic Appeal 